\title{
Physical Fatigue Perawat Saat Bekerja di Ruang Intensive Care Unit
}

\author{
Hammad $^{1(\mathrm{CA})}$ \\ ${ }^{1(\mathrm{CA})}$ Jurusan Keperawatan, Poltekkes Kemenkes Banjarmasin, Indonesia; hammad.martapura@gmail.com \\ (Corresponding Author)
}

\begin{abstract}
Physical Fatigue of nurses in the ICU is a condition that can be a burden or obstacle for nurses in providing quality nursing care for critical patients who are being treated in the ICU. This study identified the incidence of physical fatigue experienced by nurses in intesive care room. The research was conducted by using a survey using a population of nurses in the ICU room at the RSUD Martapura and RSUD Idaman Banjarbaru using cluster sampling. The results showed that most of the nurses at Martapura Hospital experienced moderate psychological fatigue and the majority of Banjarbaru Hospital nurses experienced mild The nurse management.must have right strategy to reduce the workload and prevent fatigue on nurses to increase quality care in ICU.
\end{abstract}

Keywords: physical fatigue; nurse; intensive care unit

\begin{abstract}
ABSTRAK
Physical Fatigue perawat di ICU merupakan kondisi yang dapat menjadi beban ataupun hambatan perawat dalam memberikan asuhan keperawatan yang berkualitas bagi pasien kritis yang sedang dirawat di ruang ICU. Penelitian ini mengidentifikasi kejadian physical fatigue yang dialami perawat di ruang ICU. Riset dilakukan dengan survei menggunakan populasi perawat di ruang ICU RSUD Martapura dan RSUD Idaman Banjarbaru yang secara cluster sampling. Hasil penelitian menunjukkan sebagian besar perawat RSUD Martapura mengalami kelelahan psikologis sedang dan perawat RSUD Banjarbaru mayoritas ringan. Perlu strategi yang tepat untuk meningkatkan mengurangi beban kerja dan mecegah adanya fatigue pada perawat oleh pihak manajemen perawat untuk meningkatn kualitas asuhan keperawatan.
\end{abstract}

Kata Kunci : physical fatigue; perawat; intensive care unit

\section{PENDAHULUAN}

Pelayanan yang profesional dalam memberikan asuhan keperawatan yang berkualitas dituntut kepada semua perawat pada setiap layanan kesehatan/keperawatan baik di rumah sakit, puskesmas maupun di komunitas ; tidak terkecuali terhadap perawat Intesive Care Unit (ICU) (Chamberlain et al., 2018; Nursalam et al., 2018; Yue et al., 2015). Namun dalam kenyataaannya ada banyak faktor yang dapat mempengaruhi kinerja perawat dalam memberikan asuhan keperawatan berkualitas dan profesional dimana salah satunya seringkali perawat mengalami kelelahan baik secara fisik maupun psikologis dikarenakan beban kerja yang tinggi (Roja et al., 2015; Tao et al., 2015; Wong \& Olusanya, 2017a, 2017a). 
Perawat di ICU sangat rentan mengalami berbagai kondisi stress di ruang keperawatan kritis dimana perawat dituntut selalu siap dan siaga terhadap berbagai perubahan hemodinamik pasien yang bisa berubah tiba-tiba dan atau begitu cepat. Perawat mengalami tingkat stres yang tinggi, beban kerja yang berat, dan sesekali bahkan mungkin mengalami cedera ketika menjaga pasien. Mayoritas perawat berjuang dengan mengelola pasien dan rentan terhadap physical fatiguedan psikologis (Bayuo \& Agbenorku, 2018, 2018; Nguyen et al., 2018; Wong \& Olusanya, 2017a, 2017a, 2017b).

Unit perawatan intensif (ICU) adalah unit dengan sakit kritis pasien, yang karena situasi dan kompleksitas perawatannya, mungkin rentan terhadap insiden keselamatan pasien (Bayuo \& Agbenorku, 2018; Nguyen et al., 2018; Romare et al., 2018; Sousa \& Mourão, 2018; Wong \& Olusanya, 2017a). Para perawat ICU sering mengalami physical fatiguekarena waktu yang lama dihabiskan untuk memastikan keselamatan pasien dan diri mereka sendiri. Physical fatiguediperparah pasien- pasien yang beresiko tinggi karena mereka mengalami penurunan kesadaran sampai koma sehingga resiko terjadi kecelakaan, seperti jatuh dari tempat tidur. Merawat pasien yang mengamuk karena Delirium mungkin sepuluh kali lebih berat daripada pasien biasa atau kritis karena semua aktivitas dan emosi mereka tidak terlihat. (Yue et al., 2015). Kondisi seperti ini tentu akan menimbulkan kelelahan baik secara fisik dan psikologis kepada perawat yang bertugas di ICU. (Bayuo \& Agbenorku, 2018; Nguyen et al., 2018; Tao et al., 2015; Wong \& Olusanya, 2017a).

Hampir 50\% dari perawat kritis memiliki tingkat gejala kelelahan yang tinggi. Sebuah survei barubaru ini dari Amerika Serikat menunjukkan prevalensi 55\% di antara dokter perawatan kritis, tertinggi dalam spesialisasi medis yang disurvei (Wong \& Olusanya, 2017a). Sebagian besar perawat juga melaporkan variasi beban kerja $(84,15 \%)$, kelebihan kuantitatif (76,8\%), tanggung jawab atas kehidupan masyarakat $(69,5 \%)$ dan kurangnya kontrol yang dirasakan $(63,41 \%)$, namun, $85,4 \%$ puas dengan perawat di tempat kerja mereka. . Selain itu, tingkat kelelahan emosional yang tinggi dilaporkan oleh sebagian besar peserta (80\%), sementara kurang dari sepertiga melaporkan tingkat depersonalisasi yang tinggi (Elshaer et al., 2018).

Insiden kelelahan di kalangan perawat tampaknya meningkat dari waktu ke waktu , meskipun peningkatan kesadaran dan kemampuan diagnostik perawat mungkin ikut berkembang lebih baik. Namun peningkatan kelelahan perawat dapat berdampak kepada penurunan kepuasan pasien maupun keluarga terhadap layanan asuhan keperawatan, peningkatan morbiditas dan mortalitas, adanya PTSD dan akan menimbulkan turn out atau turn over intention perawat untuk berhenti atau keluar dari ruang perawatan ICU (Bayuo \& Agbenorku, 2018; Chipu et al., 2017; Kim \& Shim, 2018; Lagerlund et al., 2015; Romare et al., 2018; Wong \& Olusanya, 2017a)

\section{METODE}

Riset ini dilakukan dengan mengevaluasi Physical Fatigue yang dialami oleh perawat pada dua ruang ICU yang berbeda. Partispan adalah perawat ruang ICU RSD Idaman Banjarbaru sebanayak 15 orang dibandingkan dengan perawat di ruang ICU RSUD Ratu Zalecha Martapura sejumlah 16 orang. Yang ditentukan dengan Probability Sampling teknik Cluster Sampling. Kelelahan diukur dengan Piper Fatigue Scale (PFS; $\alpha=0,98, r=0.80$ dan strong test-retest agreement $=0.98$ ) 


\section{HASIL}

Tabel 1. Karakteristik responden berdasar usia

\begin{tabular}{cccccc}
\hline \multirow{2}{*}{ No. } & Batasan Umur & \multicolumn{2}{c}{ RSUD Ratu Zalecha Martapura } & \multicolumn{2}{c}{ RSD Idaman Banjarbaru } \\
\cline { 3 - 6 } & & $\mathrm{f}$ & $\%$ & $\mathrm{f}$ & $\%$ \\
\hline 1 & $17-25$ tahun & 0 & 0 & 2 & 13,33 \\
2 & $26-35$ tahun & 11 & 68,75 & 8 & 53,34 \\
3 & $36-45$ tahun & 5 & 31,25 & 5 & 33,33 \\
& Jumlah & 16 & 100 & 15 & 100 \\
\hline
\end{tabular}

Tabel 1 diatas menunjukkan bahwa paling banyak responden berusia 26-35 tahun untuk RSUD Ratu Zalehca Martapura dan RSUD Idaman Banjarbaru.

Tabel 2. Distribusi Frekuensi Physical Fatigue Perawat di RSD Idaman Banjarbaru dan RSUD Ratu Zalecha Martapura

\begin{tabular}{|c|c|c|c|c|c|}
\hline \multirow{2}{*}{ No } & \multirow{2}{*}{ Level } & \multicolumn{2}{|c|}{ RSUD Ratu Zalecha Martapura } & \multicolumn{2}{|c|}{ RSD Idaman Banjarbaru } \\
\hline & & $\mathrm{f}$ & $\%$ & $\mathrm{f}$ & $\%$ \\
\hline 1 & Ringan & 4 & 25 & 9 & 60 \\
\hline 2 & Sedang & 8 & 50 & 5 & 33 \\
\hline 3 & Berat & 4 & 25 & 1 & 7 \\
\hline \multicolumn{2}{|c|}{ Total } & 16 & 100 & 15 & 100 \\
\hline
\end{tabular}

Berdasarkan Tabel 2 kondisi Physical Fatigue perawat di RSUD Ratu Zalecha Martapura terbanyak pada level sedang, 8 orang (50\%), sementara untuk petugas di RSUDD Idaman Banjarbaru mayoritas hanya ringan 9 orang partisan $(60 \%)$ walaupun pada kedua rumah sakit ini juga ada kondisi dimana perawat dapat mengalami kondisi Physical Fatigue pada level berat.

\section{PEMBAHASAN}

Profesional keperawatan yang bekerja di Intensive Care Unit (ICU) telah dicatat dihadapkan dengan tingkat stres yang tinggi yang berasal dari kondisi kritis pasien, keputusan cepat yang diperlukan untuk perawatan pasien dan lingkungan perawatan yang kompleks. Terlepas dari kenyataan ini, ICU ada untuk mengelola pasien dengan berbagai kondisi atau orang sakit kritis dari kelompok usia yang berbeda. Jadi dari segi kondisi penyakit, ada area seperti Surgical Intensive Care Unit (SICU) dan Cardiac Intensive Care Unit. Demikian pula dalam hal usia, ada Unit Perawatan Intensif Anak dan Unit Perawatan Intensif Neonatal. Karena ICU ini mungkin memiliki karakteristik sebagai lingkungan kerja yang penuh tekanan, ada alasan untuk percaya bahwa perbedaan mereka dalam hal sifat pasien yang dirawat dapat menyiratkan bahwa pengalaman stresor(Bayuo \& Agbenorku, 2018; Chipu et al., 2017; Wong \& Olusanya, 2017a). 
Perbedaan di antara perawat yang bekerja di bidang intensive care jelas ada dibandingkan dengan perawat ruangan lain ; pasien yang masuk ruang perawatan ICU adalah pasien - pasien dengan tingkat morbiditas dan mortalitas yang cukup besar. Meskipun perawatan pasien kritis di ruang ICU membutuhkan keahlian dari berbagai praktisi perawatan kesehatan, sebagian besar persyaratan perawatan telah dicatat sebagai fungsi keperawatan(Engwall et al., 2015; Huang et al., 2010; Kim \& Shim, 2018; Nguyen et al., 2018). Ini termasuk pemantauan fisiologis intensif, mempertahankan nutrisi yang tepat, perawatan luka, penilaian dan pengelolaan nyeri serta pemantauan hemodinamik dan tanda-tanda vital yang ketat. Dengan demikian, perawat yang bekerja di Unit Perawatan Intensif dapat melakukan beberapa peran yang mungkin tidak ada di ruangan perawatan lain yang dapat menjadi begitu melelahkan secara fisik dan emosional bagi perawat. Pengalaman kelelahan jangka panjang dan minat yang berkurang, biasanya dalam konteks perawat ICU (Bayuo \& Agbenorku, 2018; Chipu et al., 2017; Yue et al., 2015). Hal tersesbut muncul sebagai hasil dari periode pengeluaran energi yang banyak di tempat kerja sementara pemulihannya terlalu sedikit.. Physical Fatigue mungkin mempengaruhi perawat ICU dalam bentuk apa pun, namun, perawat ICU dengan stres tinggi dapat menyebabkan lebih banyak kelelahan daripada perawat dengan stres yang lebih rendah. Petugas kesehatan lainnya bisa saja juga mendapatkan Physcal Fatigue, namun, variasi luas dalam prevalensi fatigue tingkat yang lebih tinggi dilaporkan di antara petugas kesehatan yang bekerja dalam keadaan darurat departemen (ED) dan unit perawatan intensif (ICU) sebagaimana adanya terkena tingkat stres kerja yang tinggi (Elshaer et al., 2018; Lagerlund et al., 2015; Mudallal et al., 2017; Sousa \& Mourão, 2018; Vifladt et al., 2016; Wong \& Olusanya, 2017a).

Faktor yang diketahui meningkatkan risiko Physcal Fatigue yang dapat dikaitkan dengan perawatan pasien kritis, angka kematian yang tinggi, keadaan kerja yang tidak tepat, dan kurangnya waktu untuk memenuhi kebutuhan pasien, sehingga mereka mengalami tingkat stres di luar kapasitas koping mereka yang dapat mengakibatkan burnout yang akan mendorong terjadinya turn out atau turn over dari ruang perawatan intensive care. . Physcal Fatigue telah dikaitkan dengan penurunan kualitas perawatan, dan tingginya tingkat ketidakhadiran dan pergantian di antara petugas kesehatan, semuanya yang memiliki konsekuensi di sektor kesehatan(Engwall et al., 2015; Huang et al., 2010; Kesgin \& Kublay, 2014; Romare et al., 2018).

Berdasarkan hasil penelitian tingkat physical fatigue lebih dirasakan oleh perawat ICU RSUD Ratu Zalecha Martapura dengan kategori sedang, sedangkan perawat ruang ICU RSDI Banjarbaru dengan kategori physical fatigue dalam kategori ringan. Berdasarkan hasil wawancara dengan perawat di RSUD Ratu Zalecha Martapura selama pengumpulan data penelitian, perawat ruang ICU mengatakan bed pasien hampir selalu terisi serta pergantian atau selang waktu bed yang kosong untuk diisi oleh pasien baru juga cepat sehingga perawat memiliki tugas yang lebih banyak. Hal tersebut berbeda dengan ruang ICU RSD Idaman Banjarbaru dimana berdasarkan hasil wawancara dengan supervisor, ruang ICU mereka jarang dalam keadaan full pasien terus menerus. Bahkan seringkali dalam satu shift tidak ada sama sekali pasien yang dirawat disana. Berdasarkan keterangan tersebut dapat disimpulkan bahwa perawat ICU di RSUD Ratu Zalecha menerima beban kerja yang lebih banyak dibandingkan perawat ICU di RSD Idaman Banjarbaru. Hal ini sejalan dengan penelitian yang dilakukan oleh Sakinah, dkk, (2012) yaitu adanya 
hubungan antara beban kerja dengan tingkat kelelahan. Beban kerja yang berlebihan atau rendah dapat menimbulkan kelelahan kerja.

Kelelahan perawat adalah perasaan subjektif dari kelelahan (dialami oleh perawat) yang secara fisik dan penetratif mental. Hal ini berkisar dari kelelahan hingga keletihan yang berat yang dapat mengganggu kemampuan fisik dan kognitif individu Kelelahan adalah konsep yang kompleks baik subjektif maupun non-spesifik yang terdiri dari faktor fisiologis, psikologis dan sosial-ekonomi. Perawat yang bekerja dengan kelelahan yang tinggi, bila dibiarkan, akan menyebabkan terjadinya kelelahan kerja. Hasil dari penelitian tentang kelelahan diantara staf keperawatan menggambarkan bahwa perawat tersebut memperlihatkan indikasi stres kerja kejadiannya meningkat sesuai dengan pertambahan umur (Chamberlain et al., 2018; Engwall et al., 2015; Huang et al., 2010; Kesgin \& Kublay, 2014; Nursalam et al., 2018; Roja et al., 2015; Romare et al., 2018; Yue et al., 2015). Kelelahan dapat fisik atau psikologisatau kombinasi dari dua dan dapat menyebabkan dikompromikan pengambilan keputusan, waktu reaksi, dan berpikir kritis; itu juga dapat negatif mempengaruhi kesehatan umum (Chamberlain et al., 2018; Elshaer et al., 2018; Kim \& Shim, 2018; Mudallal et al., 2017; Roja et al., 2015; Tao et al., 2015; Vifladt et al., 2016).

\section{KESIMPULAN}

Physical Fatigue merupakan kondisi yang dirasakan pada oleh perawat baik di ruang ICU RSUD Ratu Zalecha Martapura maupun RSUD Idaman Banjarbaru dimana kondisi ini perlu menjadi perhatian bagi pihak manajemen keperawatan dan pihak manajemen RS agar dapat dapat memberikan strategi yang tepat menurunkan level physical fatigue sehingga kualitas pelayanan asuhan keperawatan dapat selalu optimal.

\section{DAFTAR PUSTAKA}

Bayuo, J., \& Agbenorku, P. (2018). Coping strategies among nurses in the Burn Intensive Care Unit: A qualitative study. Burns Open, 2(1), 47-52. https://doi.org/10.1016/j.burnso.2017.10.004

Chamberlain, D., Pollock, W., \& Fulbrook, P. (2018). ACCCN Workforce Standards for Intensive Care Nursing: Systematic and evidence review, development, and appraisal. Australian Critical Care, 31(5), 292-302. https://doi.org/10.1016/j.aucc.2017.08.007

Chipu, M. G., Kearns, I., \& Nel, W. E. (2017). Experiences of registered nurses caring for patients with an open abdomen in an intensive care unit in Gauteng. Health SA Gesondheid, 22, 166-173. https://doi.org/10.1016/j.hsag.2017.01.009

Elshaer, N. S. M., Moustafa, M. S. A., Aiad, M. W., \& Ramadan, M. I. E. (2018). Job Stress and Burnout Syndrome among Critical Care Healthcare Workers. Alexandria Journal of Medicine, 54(3), 273277. https://doi.org/10.1016/j.ajme.2017.06.004

Engwall, M., Fridh, I., Johansson, L., Bergbom, I., \& Lindahl, B. (2015). Lighting, sleep and circadian rhythm: An intervention study in the intensive care unit. Intensive and Critical Care Nursing, 31(6), 325-335. https://doi.org/10.1016/j.iccn.2015.07.001

Huang, Y. C., Huang, S. J., \& Ko, W. J. (2010). Survey of Do-not-resuscitate Orders in Surgical Intensive Care Units. Journal of the Formosan Medical Association, 109(3), 201-208. https://doi.org/10.1016/S0929-6646(10)60043-5 
Kesgin, M. T., \& Kublay, G. (2014). Using the Omaha System in Occupational Health Nursing Applications: Advantages of a Common Language in the Diagnosis, Intervention and Evaluation of Nurses' Health Problems. Procedia - Social and Behavioral Sciences, 152(Birol 2004), 488-494. https://doi.org/10.1016/j.sbspro.2014.09.238

Kim, I. J., \& Shim, H. W. (2018). Subjectivity About Turnover Intention Among Male Nurses in South Korea: A Q-Methodological Study. Asian Nursing Research, 12(2), 113-120. https://doi.org/10.1016/j.anr.2018.04.002

Lagerlund, M., Sharp, L., Lindqvist, R., Runesdotter, S., \& Tishelman, C. (2015). Intention to leave the workplace among nurses working with cancer patients in acute care hospitals in Sweden. European Journal of Oncology Nursing, 19(6), 629-637. https://doi.org/10.1016/j.ejon.2015.03.011

Mudallal, R. H., Saleh, M. Y. N., Al-Modallal, H. M., \& Abdel-Rahman, R. Y. (2017). Quality of nursing care: The influence of work conditions, nurse characteristics and burnout. International Journal of Africa Nursing Sciences, 7, 24-30. https://doi.org/10.1016/j.ijans.2017.06.002

Nguyen, H. T. T., Kitaoka, K., Sukigara, M., \& Thai, A. L. (2018). Burnout Study of Clinical Nurses in Vietnam: Development of Job Burnout Model Based on Leiter and Maslach's Theory. Asian Nursing Research, 12(1), 42-49. https://doi.org/10.1016/j.anr.2018.01.003

Nursalam, N., Fibriansari, R. D., Yuwono, S. R., Hadi, M., Efendi, F., \& Bushy, A. (2018). Development of an empowerment model for burnout syndrome and quality of nursing work life in Indonesia. International Journal of Nursing Sciences, 5(4), 390-395. https://doi.org/10.1016/j.ijnss.2018.05.001

Roja, Z., Kalkis, H., \& Roja, I. (2015). Measuring Muscle Fatigue in Relation to the Workload of Health Care Workers. Procedia Manufacturing, 3(Ahfe), 4189-4196. https://doi.org/10.1016/j.promfg.2015.07.394

Romare, C., Hass, U., \& Skär, L. (2018). Healthcare professionals' views of smart glasses in intensive care: A qualitative study. Intensive and Critical Care Nursing, 45, 66-71. https://doi.org/10.1016/j.iccn.2017.11.006

Sousa, A. R. C., \& Mourão, J. I. de B. (2018). Burnout in anesthesiology. Brazilian Journal of Anesthesiology (English Edition), 68(5), 507-517. https://doi.org/10.1016/j.bjane.2018.04.007

Tao, H., Ellenbecker, C. H., Wang, Y., \& Li, Y. (2015). Examining perception of job satisfaction and intention to leave among ICU nurses in China. International Journal of Nursing Sciences, 2(2), 140-148. https://doi.org/10.1016/j.ijnss.2015.04.007

Vifladt, A., Simonsen, B. O., Lydersen, S., \& Farup, P. G. (2016). The association between patient safety culture and burnout and sense of coherence: A cross-sectional study in restructured and not restructured intensive care units. Intensive and Critical Care Nursing, 36, 26-34. https://doi.org/10.1016/j.iccn.2016.03.004

Wong, A. V. K., \& Olusanya, O. (2017a). Burnout and resilience in anaesthesia and intensive care medicine. BJA Education, 17(10), 334-340. https://doi.org/10.1093/bjaed/mkx020

Wong, A. V. K., \& Olusanya, O. (2017b). Burnout and resilience in anaesthesia and intensive care medicine. BJA Education, 17(10), 334-340. https://doi.org/10.1093/BJAED/MKX020

Yue, P., Wang, L., Liu, C., \& Wu, Y. (2015). A qualitative study on experience of nurses caring for patients with delirium in ICUs in China: Barriers, burdens and decision making dilemmas. International Journal of Nursing Sciences, 2(1), 2-8. https://doi.org/10.1016/j.ijnss.2015.01.014 